\title{
Refurbished Computers for Adult Learners at Home or in Class
}

David J. Rosen, Newsome Associates

Each Technology Solutions for Adult Basic Skills Challenges column begins with a common challenge facing adult basic skills practitioners. Solutions offered for these challenges, at least in part through the use of technology, include hardware, software applications such as websites, course management systems, learning management systems, and apps for mobile devices. Each article begins with a description of the challenge, and then examines solutions that involve the use of technology.

\section{Description of the Challenge}

Many adult foundational (basic) skills learners have smartphone access to the internet, and they may have benefited from remote learning, especially during the COVID-19 pandemic. Others who have this access have been frustrated in using asynchronous instruction websites, especially when they need to write. With health care now increasingly being provided remotely through telehealth, many health care providers and patients have been frustrated by the limitations of two-way communication that is limited by telephone and even smartphone telehealth. Adult learners increasingly say they need access from a home larger-screen digital device such as a desktop or laptop computer or possibly a Chromebook or electronic tablet. However, they may believe that they may not be able to afford one.

\section{Solution}

One solution for an adult learner may be to purchase a low-cost refurbished computer, or for an adult basic skills program to seek grants to purchase these for their students who have been, and may yet be, learning entirely remotely or in a hybrid model that involves some in-person and some online learning from home.

In this Technology Solutions column, we are looking at computer refurbishing options and some typical questions that adult basic skills program administrators, instructors and adult learners may have about refurbished computers. Although this column's intended audience is usually adult basic education practitioners, in this case the information here is also intended for adult learners who are fairly good readers in English or whose teachers help them to get this information.

\section{What Does "Refurbished" Mean?}

In all cases a refurbished computer should include a factory reset, cleaning, and testing of the machine, but it could also include repairs or replacement of faulty components. Computer refurbishers want their products to be "good as new," so their customers are satisfied. That's why most offer a warranty and return policy and, if a problem is discovered, will replace the computer 
or repair it. Some computers are refurbished by their manufacturer. There are for-profit and notfor-profit refurbishers. The not-for-profit ones generally are in business to locally close the digital divide, as are some of the for-profit refurbishers.

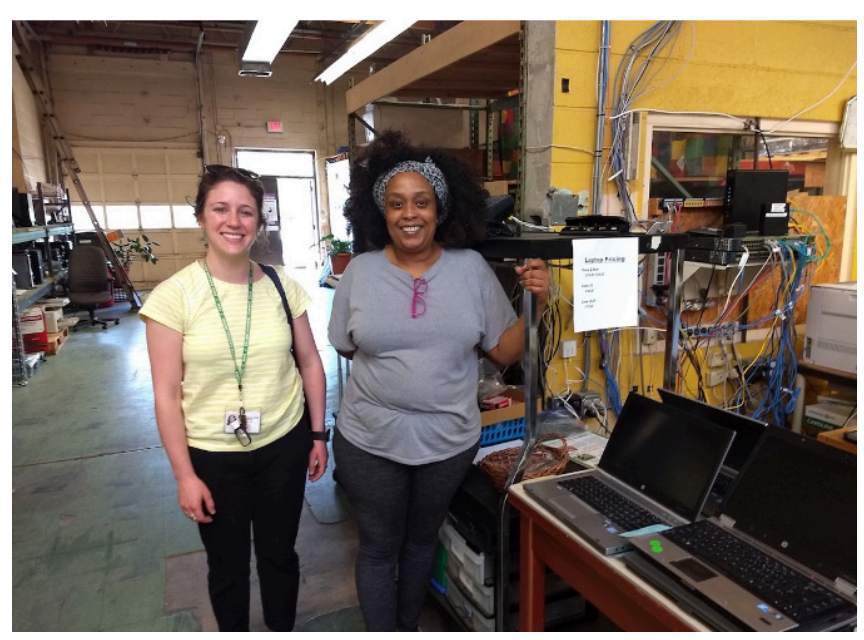

Team Children, in greater Philadelphia, has distributed over 21,000 low-cost, high quality refurbished desktops and laptops www. teamchildren.org

\section{Are All Refurbished Computers Good?}

As you might expect, this can depend on who is refurbishing them and what their refurbishment procedures and quality assurance policies are. Refurbished does not mean low-quality; it means more affordable, although refurbished computers generally are not the latest models. To assure this quality some refurbishers test the hardware in the units more extensively than some new computers are tested. Throughout the country, and particularly in urban metropolitan areas, there are not-for-profit and for-profit computer refurbishing organizations and businesses. Some have excellent reputations, and most will offer a warranty of at least a year. Many are in business as part of a social mission, to reduce the digital divide and address digital equity by providing affordable or free home computers to low-income families. Regardless, you may want to find out what a particular seller's refurbishment process entails.

\section{Where Do Refurbished Computers Come From?}

They may be returns or canceled orders which cannot be resold as new, defective returns that have been fixed and retested, or computers with small defects like scratches or minor dents that make them impossible to sell as new. If they are sold by a community-based, not-for-profit organization, they may have been donated, often not by individuals but by large companies, universities, or hospitals; these computers may just be too old to meet the donor organization's standards, and the company or organization may donate a large number of the same model that was bought for a large number of employees at the same time. For adult foundational skills programs that need to purchase a large number of computers, for example for a computer lab, it is very helpful to have the same model.

\section{What Do Refurbished Computers Typically Cost?}

That varies, but in sampling a few for this article I found that they ranged in price from $\$ 100$ to \$500, but most were under $\$ 300$. Most refurbished Chromebooks, for example at Walmart, were under \$100. I have read that refurbished computers generally cost about 30 to 50 percent less than the retail price of a new computer.

\section{How Do I Find a Local Computer Refurbishing Organization?}

Digitunity's Alliance for Technology Refurbishing and Repair (AFTRR) is one possibility. They host a map locator listing over 100 locations of 
nonprofit computer refurbishers at https://www. aftrr.org/map-locator/You could also try doing a Coogle search using "computer refurbisher" or "refurbished computer" along with your zip code. You may get computer repair businesses from such a search as well as computer refurbishers. If you are looking to purchase refurbished computers online, just search for "refurbished computer."

One of the organizations on the AFTRR map is Human-I-T https://www.human-i-t.org/. It's a national organization that provides refurbished computers to individuals and to not-for-profit organizations across the United States. Human-I-T sells computers online too. They offer refurbished desktop and laptop computers, low-cost mobile internet, and affordable computer repair

\section{What Do I Need to Think About Before I Contact a Computer Refurbishing Program?}

If you are purchasing computers for your adult foundational skills program, you may first want to figure out how many computers you need, what your budget can afford, if you need all the computers to be the same make, model, and year (or not), whether you want desktop or laptop models, or Chromebooks; whether you also need tech support and computer maintenance and repair; and decide how soon you need the computers. If you are dealing with a local computer refurbisher they may ask you to pick up the computers and, depending on what type-desktop or laptop-and how many you may need, a van or a truck or other large vehicle may be needed. If you are purchasing refurbished computers to loan, or give to students to use at home, you will first need to figure out their device needs. This is often done through a written or oral survey or through a program intake conversation interview. In the interview, you will want to zero in on how the computer will be used and for what purposes so that you can get a sense of what storage capacity (photos, images, heavy coding load?) is needed. You will want to know what students can afford if they are paying for all or part of the computer. You will also want to know about whether they need a desktop or a laptop, what their battery needs may be, what screen size they need and if they need Wi-Fi access. You may want to ask what accessories-printer, headphones, and other peripherals-they may need. Some of these questions are also relevant when you are figuring out what you need for computers that students will use in your program. If you want to outfit a computer lab, you may want the same kind of computers you are buying for students to use at home.

You may also want to think about what software you need to have loaded on the computers: an Operating System is standard, but you may also want office software; some refurbishes will load free open source office programs (word processing, spreadsheets, slides, etc.) You should ask if security software, including anti-virus software and perhaps others, is offered in the standard price. Also, some AFTRR members solely serve people with disabilities and will configure a student's refurbished computer to their needs.

\section{Do Computer Refurbishers Offer Digital Literacy Skills Training?}

Some, especially the not-for-profit ones, do. If your program offers digital literacy skills training for your community, you may want to let the refurbisher know about that and provide them with some of your business cards or flyers. Perhaps they would be interested in referring their clients to you as digital literacy learners 


\section{Can Our Adult Foundational Skills Program Seek Funding for Purchasing Refurbished Computers?}

Sometimes yes. Since the beginning of the pandemic many charitable foundations and government grants allow programs to purchase computers for students to use at a school or an education program or at home for education purposes for children and adults. For example, Digitunity (digitunity. org) allows eligible organizations (such as nonprofit organizations, government agencies, or schools who serve people who are at risk or marginalized or economically disadvantaged) to register to receive technology donations from individuals and businesses. See https:// digitunity.org/get-involved/receive-equipment/

\section{If Our Program Purchases Refurbished Computers, How Do They Get to Us?}

It depends. If you buy them online, for example online from a nonprofit refurbisher such as Human-I-T or InterConnection, or a for-profit organization such as Amazon or Walmart, or directly from a manufacturer, they will be shipped to you. If you buy from a local refurbisher, you may need to pick them up.

\section{Are There Other Advantages to Purchasing a Refurbished Computer?}

Yes. Refurbished and recycled computers, because they are used for more years, have less environmental impact.

Many thanks to my adult family literacy, library and digital inclusion colleague Karisa Tashjian at Digitunity.org whom I interviewed before writing this article. 


\section{Additional Articles}

https://www.newegg.com/insider/tips-beforebuying-refurbished-pcs/

https://generocity.org/philly/2018/05/24/ teamchildren-low-cost-refurbished-computeraudubon-nonprofit/

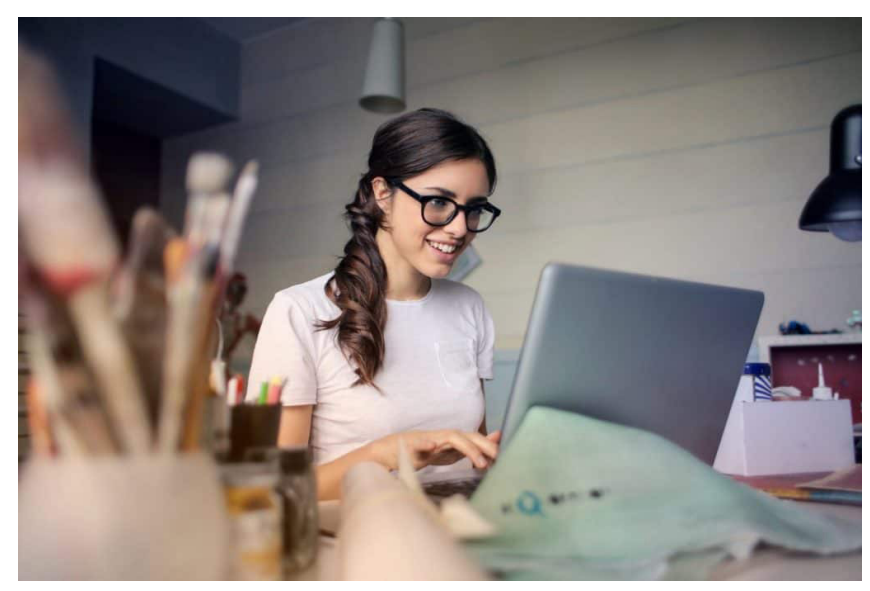

From ESL Job Exchange, "Cheap Laptops For Online ESL Teachers https://www.esljobexchange.com/ cheap-laptops-online-esl-teachers/

\section{Resource Guides}

https://cristina55219.ac-page.com/digitunityresource-guide 